Emulation-based virtual laboratories: a low-cost alternative to physical experiments in control engineering education

by Graham C. Goodwin, Adrian M. Medioli, Willy Sher, Ljubo Vlacic and James S. Welsh

Copyright (C) 2011 IEEE.

This is an author-prepared version of the article, reprinted from IEEE Transactions on Education, Vol. 54, Issue 1, p. 48-55.

http://dx.doi.org/10.1109/TE.2010.2043434

This material is posted here with permission of the IEEE. Such permission of the IEEE does not in any way imply IEEE endorsement of any of University of Newcastle's products or services. Internal or personal use of this material is permitted. However, permission to reprint/republish this material for advertising or promotional purposes or for creating new collective works for resale or redistribution must be obtained from the IEEE by writing to pubs-permissions@ieee.org. By choosing to view this document, you agree to all provisions of the copyright laws protecting it. 


\title{
Emulation-Based Virtual Laboratories: A Low-Cost Alternative to Physical Experiments in Control Engineering Education
}

\author{
Graham C. Goodwin, Fellow, IEEE, Adrian M. Medioli, Willy Sher, \\ Ljubo Vlacic and James S. Welsh
}

\begin{abstract}
This paper argues the case for emulation-based virtual laboratories in control engineering education. It demonstrates that such emulation experiments can give students an industrially-relevant educational experience at relatively low cost. The paper also describes a particular emulation-based system that has been developed with the aim of giving students an introduction to real world control engineering design.
\end{abstract}

Index Terms

Composite teaching techniques, emulation-based laboratories, engineering education, low-cost laboratories, teaching resources, virtual laboratories.

\section{INTRODUCTION}

Education in applied areas, such as control engineering, takes many forms ranging from highly theoretical to deeply vocational.

Typically, broad parameters are set by professional accreditation bodies. However, these parameters usually cover the "what" rather than the "how." Thus individual instructors are left with considerable flexibility in the way that material is delivered. Indeed, the emphasis often simply reflects whether the instructor has been principally involved in research or has a strong industrial background.

Another factor is that graduates respond to different emphases in their education. For example, those who go on to complete a higher degree will typically need a strong foundation in basic scientific principles, whereas those who choose to work in the profession typically need a greater emphasis on practical relevance.

One can debate whether there is actually a difference between good theory and good practice. A quote, usually attributed to Lewin [1] but sometimes attributed to Einstein or Maxwell, is "There is nothing more practical than a good theory." However this is counterbalanced by Bertrand Russell who reportedly said "There must be an ideal world, a sort of mathematician's paradise where everything happens as it does in the text books."

If this debate between theory and practice is deemed to be controversial, then consolation may be found in the words of Bertrand Russell who said "The most savage controversies are about those matters as to which there is no good evidence either way."

Indeed it is the authors' belief that one should always combine elements of theory and practice in teaching. Thus a course on control engineering without strong scientific underpinning would be superficial and dangerous but, equally, a course without reference to practical engineering design would be sterile and non-motivating. Thus some combination of theory and practice is desirable.

Graham C. Goodwin, Adrian M. Medioli and James Welsh are with the School of Electrical Engineering and Computer Science, Willy Sher is with the School of Architecture and Built Environment, The University of Newcastle, Australia. Ljubo Vlacic is with the School of Engineering, Griffith University, Australia. Email: Graham.Goodwin, Adrian.Medioli, Willy.Sher, James.Welsh@ newcastle.edu.au, L.Vlacic@griffith.edu.au. 
Consequently educators in applied areas typically seek innovative ways of exposing students to the nature of professional practice in their chosen discipline. For example, in the teaching of building, education, nursing and software engineering at the University of Newcastle, Australia, a system known as, Newcastle University Recording Academic, Professional and Individual Development (NURAPID), is used to focus students' attention on core professional skills such as communications, presentation and teamwork [2], [3].

A well rounded curriculum in, for example, control engineering, needs to combine the appropriate theoretical underpinnings with a strong emphasis on relevance. Basic theory is best presented in a directed fashion, with the instructor going through worked examples. However, in engineering, it is highly desirable that theory be connected to the real world of design. Also, this practical reinforcement needs to be interlaced with the theoretical material so that students' learning is continually punctuated by the realization that the ideas are highly relevant to the career they will undertake once they graduate.

Thus lecture courses in engineering science need to be supported by practical laboratory sessions. However, this leads to a major dilemma for educators, namely how to achieve an appropriate trade-off between cost and realism in education.

There has been substantial on-going interest in this dilemma by engineering educators and education researchers throughout the world. For example, Nickerson et al. [4] refer to economic pressures on universities and the emergence of new technologies as inspiring the creation of new systems for delivering engineering laboratories in education, especially simulation and remote access laboratories. Quoting Nickerson et al. [4]; "Advocates of simulations argue that physical laboratories needlessly consume university space and students' time. However, proponents of hands-on laboratories argue that student engineers should be exposed to real environments. Remote laboratories have appeared as a third option." Nickerson et al. have developed a model for testing the relative effectiveness of engineering laboratories in education and have tested the ideas on junior-level machine dynamics courses: "The results suggest that students learned lab content information equally well from both types of laboratories."

Other authors, see for example [5], argue that "Remote laboratories are characterized by two factors a separation, both physical and psychological, between the students and the laboratory hardware; and a technology-mediated interface that is used to close this distance. Both of these factors have been shown in the literature to affect the way in which students learn, changing the contexts in which they construct their knowledge... they are a pedagogically different learning experience." Other authors, such as [6], report that "The results from a study (on a jet thrust laboratory) indicated no significant difference in the educational outcomes between students who performed the laboratory in person or using the remote experiment."

A comprehensive review of the literature relating to hands-on, simulated and remote laboratories is given in [7] who conclude that "the boundaries among the three labs are blurred in the sense that most laboratories are mediated by computers, and that the psychology of presence may be as important as technology."

\section{LEARNING MODES}

Before discussing various possibilities for experimental work, it is helpful to place the different options in the context of alternative learning modes. The four principle learning modes, of relevance to the current paper are:

\section{A. Directed Learning}

This is the traditional approach wherein students learn by the teacher presenting the material in a highly organized fashion, including a structured development of theory, worked examples, and guided reading. Typically this type of learning is based around a single text book through which the instructor proceeds systematically. This mode of learning is sometimes referred to as conventional instruction-based. 


\section{B. Problem-Based Learning}

In this mode, learning is based on solving a set of problems using pre-specified tools see for example [8]-[11]. This methodology was first introduced at McMaster University in Canada for medical education. Indeed, Problem-Based Learning (PBL) is an integral part of the educational process in architecture and construction management at the authors' current universities [12].

Some education researchers support the use of PBL as the preferred and sole mode of instruction. However there is also evidence [13] that this can be inefficient, since students first need to learn basic theory and to see how experts solve problems before they attempt a problem on their own; that is, some form of Directed Learning is required.

Albanese and Mitchell [14] reviewed the effects of PBL on medical education. Quoting from their paper: "Compared with conventional instruction, PBL graduates perform as well, and sometimes better, in clinical examinations and faculty evaluations; and they are more likely to enter family medicine. Further faculty tend to enjoy teaching using PBL. However, PBL students, in a few instances, scored lower on basic science examinations and viewed themselves as less well prepared in the basic sciences than were conventionally trained counterparts."

\section{Research-Based Learning}

In Research-Based Learning (RBL), students are stimulated to investigate subjects in an exploratory and unconstrained fashion. Here students would typically be given a reading list and encouraged to explore the subject beyond the narrow scope of directed learning. There are many ways to integrate research into a curriculum. Details can be found in [15]. If RBL were the only mode of learning adopted, then excellent students undoubtedly would be highly stimulated, but it is likely that poorer students would feel isolated and hence perform much worse than in a directed or problem-based learning environment.

\section{Combined Strategies}

Each of the three strategies described above is accompanied by advantages and disadvantages. Thus there is merit in integrating the best of the Directed (conventional), PBL and RBL teaching concepts. This leads to combined strategies of various types.

\section{WHY HAVE EXPERIMENTAL WORK?}

Given the cost of purchasing, operating and maintaining experimental apparatus, some educators question whether it is actually necessary to have experimental work at all. On the other hand, students strongly perceive the need to relate the theoretical content of their courses to the real world.

For example, the third author of this paper has sought extensive feedback from students on the way that they perceive their course. The following quotations are typical:

Student No.1.: "Having worked in the mining industry as an electrical engineer for three years now I have good knowledge of what engineers, across the board, actually do in the real world.

Without work experience, and just going off the course content in uni, I would probably not have any idea what electrical engineers do.

The void between university and the real world is one of the most frustrating things for me. Why can't the gap be closed? Why can't an electrical engineering degree (at least) be made more practical? Why do university graduates have to be so useless when they enter the workforce?"

Student No.2.: "I have actually done some work experience but if someone asked me what sort of job I am going to be doing at the end of my degree, I couldn't give them a very good answer.

One of the major problems I had in my work experience placement was applying the theoretical knowledge I had learnt to practical applications. It seems to be that all the assignments, labs and exercises we get are aimed towards just doing problems, which is good for learning but it would be nice if each course had a couple of weeks at the end of semester going through explaining how the theory and mathematics we have learnt can be applied to real world problems." 
Student No.3.: "I work as an electrical engineer. Engineering is all about solving problems and developing the knowledge and skill to do so on the way. It is not about memorizing text books or lecture notes."

Student No.4.: "Many of the lecturers I have come across have worked only in theoretical fields and have spent their entire careers in academia.

While this leaves them with a vast amount of knowledge of their subjects, it provides them with little knowledge of how their concepts are applied in industry."

Student No.5.: "The course is pretty much all analysis (problem solving). It therefore should, at least, have a weekly lecture dedicated to how to do what we get assessed on. Would like to learn more about how we will use what we have learned in the workplace when we graduate."

Student No.6.: "Good lecturers relate course material to the real world - students like to know if there's a point to what they're learning."

The inevitable conclusion for the above feedback is that students in applied areas, such as control engineering, attach high importance to the relationship between theory and practice. Thus, some form of experimental work is highly desirable, and possibly essential, in engineering education.

\section{OPTIONS FOR EXPERIMENTAL WORK}

There are many ways that educators can give students exposure to practical experiments. Several options are discussed below:

\section{A. Pilot Plants}

At one end of the spectrum, some educators use full scale pilot plants so as to give students exposure to realistic real world design scenarios. For example, it is common in university Chemical Engineering departments to build, and operate, distillation columns to illustrate the physics and control of distillation processes. This kind of exposure for students should be applauded. However, the costs associated with designing, building, operating and maintaining such systems can be enormous! If one adds the need for additional space and associated occupational health and safety restrictions, it begins to look very unattractive.

\section{B. Simulation Experiments}

At the other end of the spectrum one finds simple simulation-style experiments which illustrate, in a relatively idealized fashion, basic scientific principles.

\section{Bench Top Experiments}

Between the above two extremes there are other alternatives. For example, one can utilize relatively simple bench top based hardware experiments. For, safety, space and operational reasons, this kind of experiment is usually restricted to relatively simple hardware. Thus typical experiments in control engineering include servo motors, tanks of water, ball and hoop apparatus or inverted pendulums.

\section{Remote Laboratories}

Another option that has recently appeared is to utilize remote laboratories where equipment is controlled via the Internet. These are often favored by education researchers because of the inherent interest and challenge in making physical experiments available remotely. However, for operational and safety reasons, this style of experiment is also usually restricted to relatively simple hardware. 


\section{E. Emulation Experiments}

A final option is to use "emulation" experiments. These are similar in spirit to simulation-based laboratories. However, the systems covered by the laboratories are designed to correspond to industrialscale problems. Moreover, the models used in this type of laboratory will typically include non-ideal features such as saturation, stiction, and measurement imperfections. Thus the results obtained from this kind of laboratory do not always coincide with pure theoretical predictions. This can worry some students. However, this better matches the reality of engineering design. The term "emulation" is used rather than "simulation" to reflect the inclusion of real world non-ideal effects.

One further very important observation is that engineers, in industrial practice, would not in general be in physical contact with the process. Instead, in control design, experimentation and implementation typically take place at a computer interface located in a process control room. The consequence of this observation is that real world plants and emulations may actually be very similar when viewed from a control engineer's perspective.

\section{EMUlation-BASEd Virtual Laboratories fOR CONTROL SySTEM Design}

Inspired by the reasoning set out above, the current paper describes a comprehensive emulation-based virtual laboratory for control engineering education [16].

The laboratories have a strong element of PBL but also include aspects of Directed Learning and, in some instances, RBL. Thus the laboratories fall into the Combined Strategies mode of learning.

A key feature of the laboratories is that there are often multiple solutions to a given problem. This captures the reality of engineering design, namely that the answers to control engineering design questions are rarely a simple number or a "yes" or "no" decision. Instead, designers are typically faced with a complex web of trade-offs [17]. Therefore, it is important that students gain an appreciation for these trade-offs as part of the education experience.

Outlined below are some of the packages currently available in the Virtual Laboratories for Control System Design (VLCSD).

\section{[1] Audio Quantization Laboratory}

The user interface is illustrated in Fig. 1.

Educational Objectives: Key issues taught by this emulation laboratory include:

(i) the impact of quantization on feedback

(ii) Bode sensitivity trade-offs

(iii) control of unstable systems

Background: This laboratory shows how feedback theory is used in high technology devices such as $\mathrm{CD}$ mastering.

\section{[2] Rolling Mill Laboratory}

The user interface is illustrated in Fig. 2.

Educational Objectives: Key issues taught by this emulation laboratory include:

(i) impact of delays on performance

(ii) use of Smith predictors to deal with delays

(iii) impact of model uncertainty on delay compensation

(iv) use of soft sensors

(v) sensitivity and complementary sensitivity trade-off

(vi) compensation of periodic disturbances

Background: This laboratory captures the difficulties inherent in center line thickness control in rolling mills. 


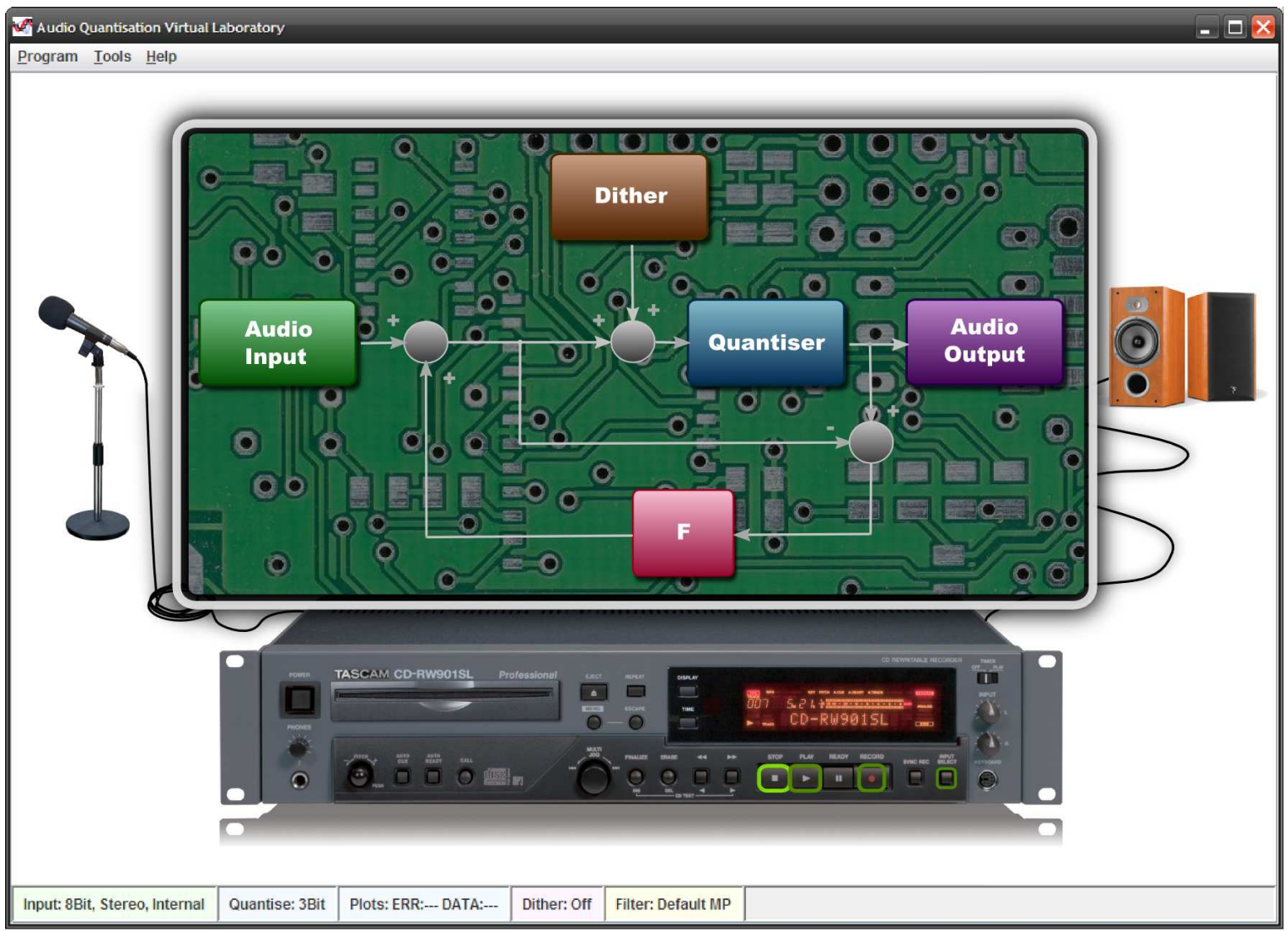

Fig. 1. Audio Quantization User Interface

\section{[3] Paper Machines}

The user interface is illustrated in Fig. 3.

Educational Objectives: Key issues taught by this emulation laboratory include:

(i) limitations of SISO control system design

(ii) impact of multi-variable interactions on decentralized controllers

(iii) multi-variable control system design

(iv) impact of actuator saturation

(v) combined effects of saturation and robustness on model uncertainty

Background: This laboratory covers industrial practice in cross directional control problems such as those found in paper machines, rolling mills, plastic extrusion and the like.

\section{[4] Continuous Casting Plant}

The user interface is illustrated in Fig. 4.

Educational Objectives: Key issues taught by this emulation laboratory include:

(i) SISO control design

(ii) feed-forward and robustness

(iii) impact of actuator imperfections

(iv) performance trade-offs inherent in overcoming actuator imperfections

Background: Continuous casting machines are widely used in steel and aluminum production. The laboratory captures key features of the associated control systems design problems. 


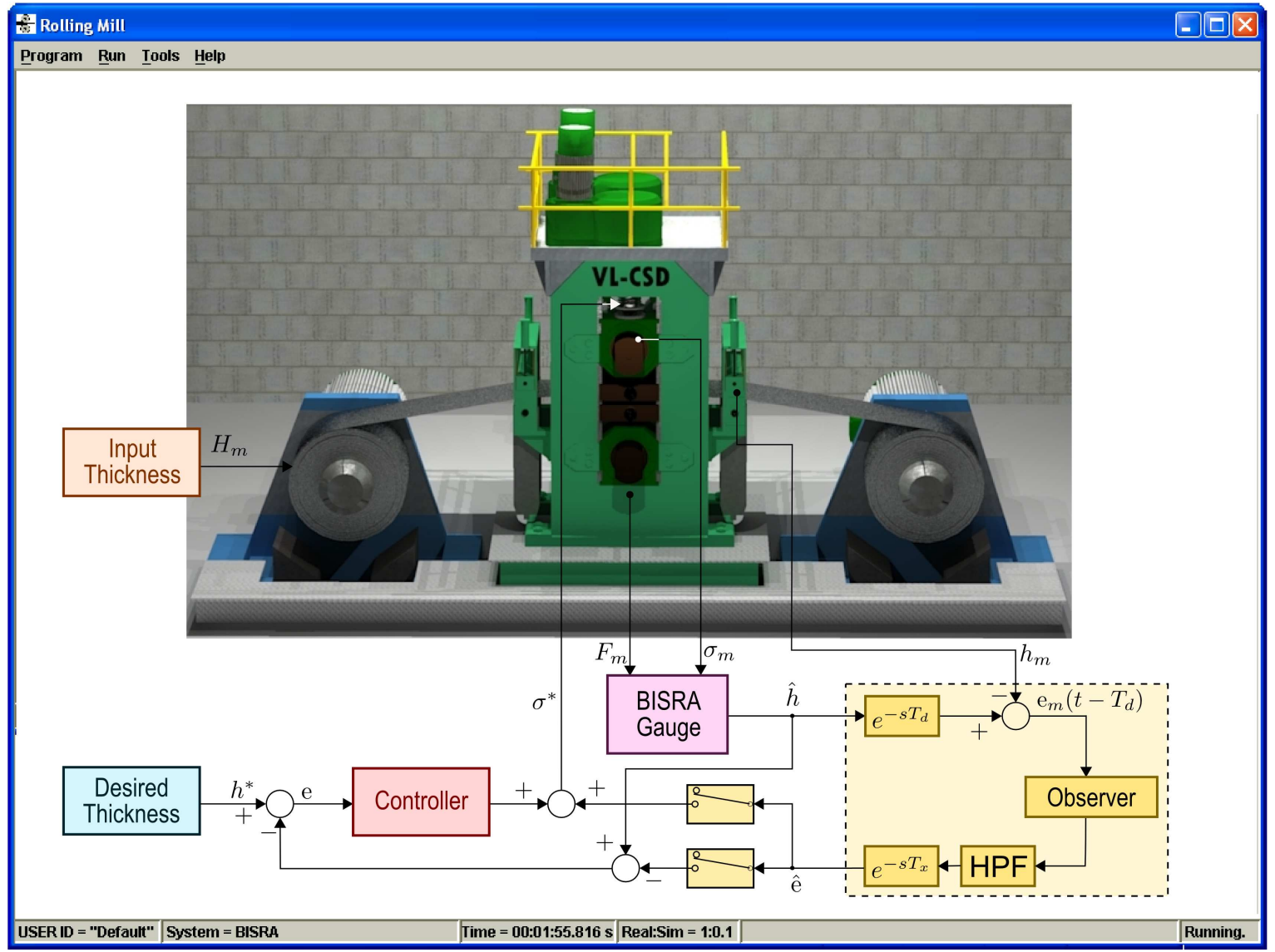

Fig. 2. Rolling Mill User Interface

\section{[5] Rocket Dynamics and Control}

The user interface is illustrated in Fig. 5.

Educational Objectives: Key issues taught by this emulation laboratory include:

(i) impact of physical construction (e.g. location of center of mass and center of pressure on open loop rocket dynamics)

(ii) closed loop control of an unstable system

(iii) impact of disturbances

Background: This laboratory covers both modeling and control of a rocket.

\section{BACKGRound to THE Design of the EMUlations Models}

The emulation models used in the Virtual Laboratories for Control System Design (VLCSD) outlined above are based on over 20 person years of experience in industrial control system design. People developing similar modules should have extensive industrial experience in the design, implementation, commissioning, testing and maintenance of industrial control systems so that this can be correctly captured in an emulation environment. Beyond that, the problem remains to package this experience into a format whereby students obtain exposure to the reality of industrial practice in a user-friendly environment. The core idea of emulation laboratories is to distill an industrial design exercise so that students can grasp the key features within a period of a few hours. In this fashion, a student can gain exposure to many years of learning in an industrial environment. This places constraints on the presentation methodology which is necessarily more restrictive than one might find, for example in Matlab ${ }^{\circledR}$, which is more free form. Also, real world design focuses on design trade-offs rather than "yes-no" type answers to hypothetical questions. This is a key element of the emulation approach. The perspective of an emulation laboratory 


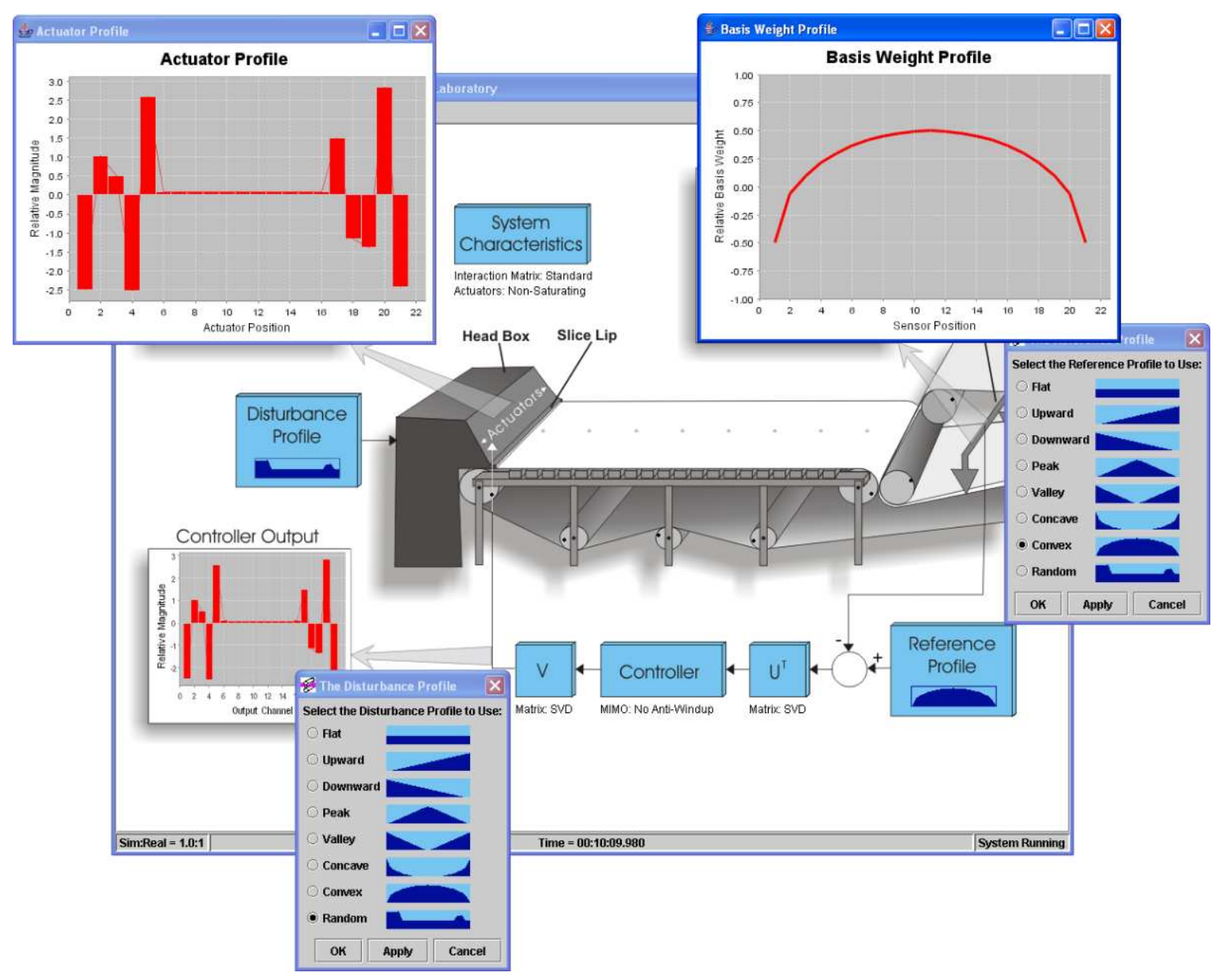

Fig. 3. Paper Machine User Interface

is always to put the problem first (as in the typical case in industry) and to bring in the theory when required. Thus the laboratories have a strong connection with problem-based learning.

\section{FuRTher Details of THE MODELS USED}

A key feature of the models used in the emulation laboratories described above is that they capture physical reality. Thus, for example, all valves operate between minimum and maximum levels and typically include hysteresis and dead-zones effects. Fluid flows are modeled as laminar or turbulent depending on physical connectivity.

To give a specific example, consider the paper machine problem. This problem features a large number of actuators (at the slice lip) and a large number of sensors (measuring basis weight). The objective of the control system is to maintain a uniform distribution of paper across the width of the machine to achieve quality requirements.

In more detail, it is typical to model the transfer function between actuators $(u)$ and sensors $(y)$ by a MIMO transfer function of the form:

$$
y(s)=M \frac{e^{-\tau_{d} s}}{\tau s+1} u(s)
$$

where $s$ denotes the Laplace transfer variable, $\tau_{d}$ and $\tau$ represent a pure delay and actuator time constant 


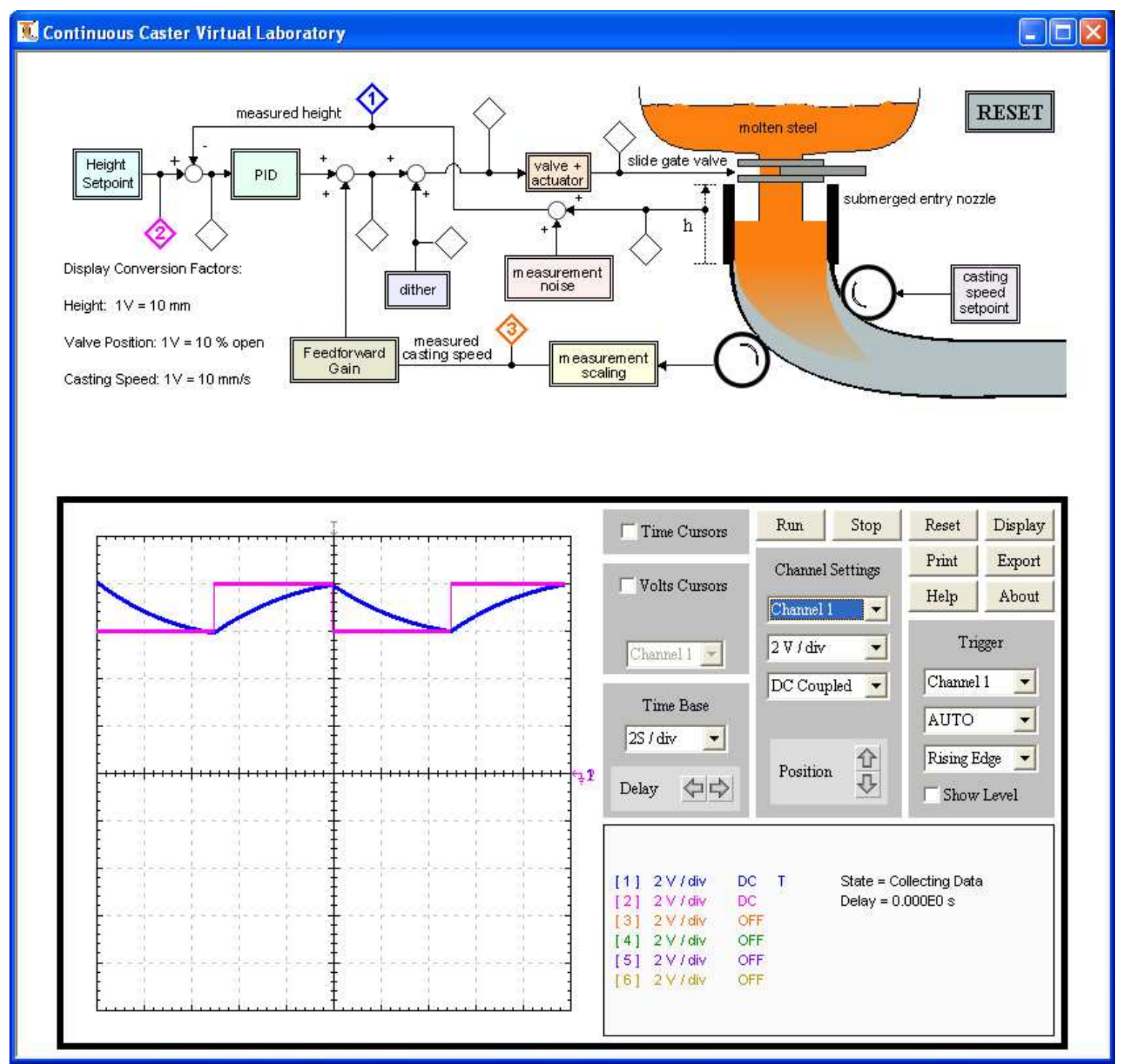

Fig. 4. Casting Machine User Interface

respectively. The Matrix $\mathrm{M}$ describes interactions and takes the form:

$$
M=k\left[\begin{array}{cccc}
1 & \alpha & \alpha^{2} & \cdots \\
\alpha & 1 & & \\
\alpha^{2} & & \ddots & \\
\vdots & & & 1
\end{array}\right]
$$

with $\alpha$ describing the impact of a single actuator on the basis weight. The interaction is illustrated in Fig. 6. The above model is the starting point of the multi-input multi-output control system design problem. However much more needs to be said to match industrial reality. Two key additional features typically met in practice are:

(i) $M$ is not precisely known and changes with operating condition.

(ii) The actuators have a (very) limited operating range.

These two key features are captured in the models used in the virtual laboratories and have a major bearing on the final control system design (as implemented in practical systems). In particular, one needs to design a robust, multi-variable controller with hard constraints on actuator movement. This is at the cutting-edge of control theory. 


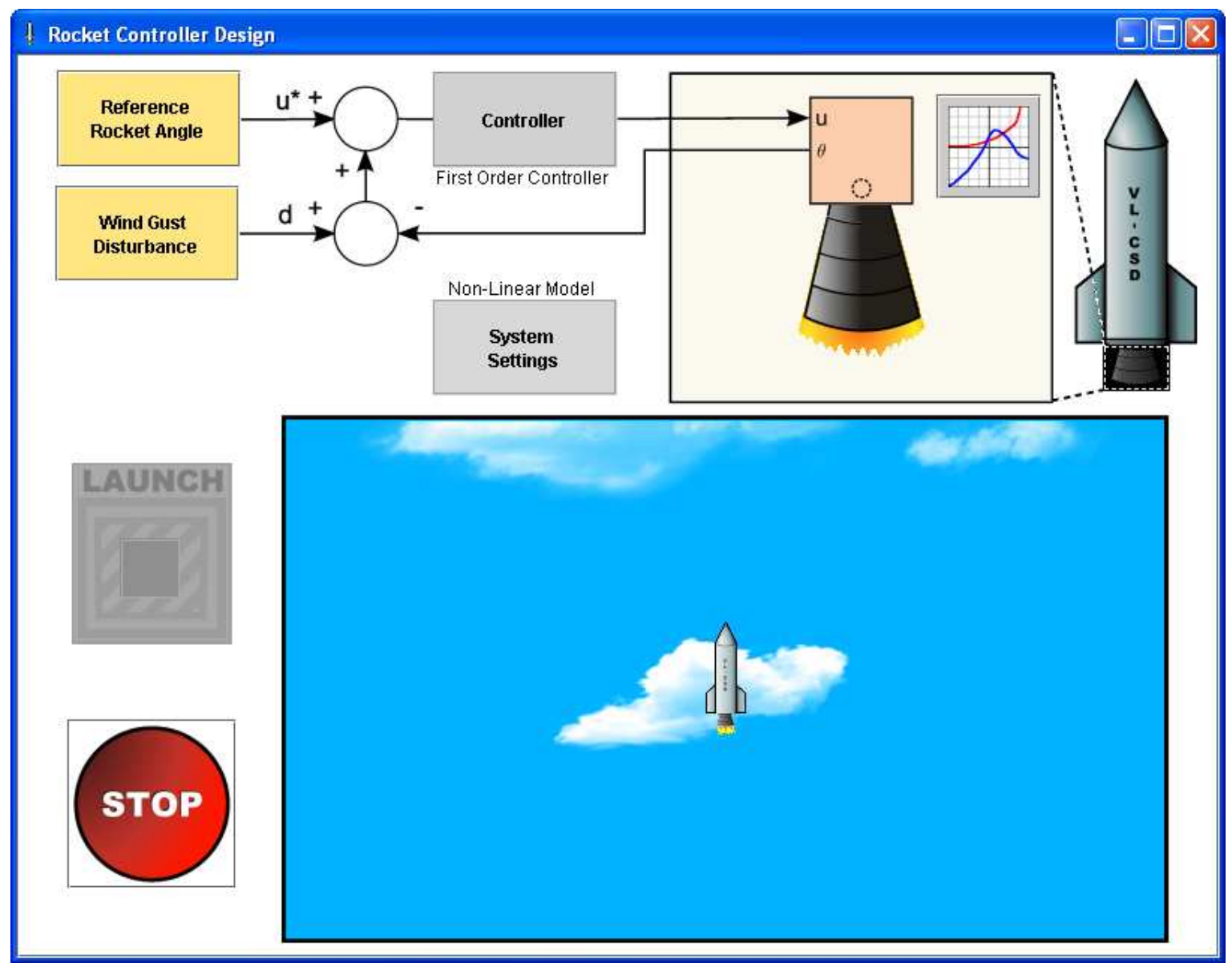

Fig. 5. Rocket Control User Interface

Attesting to the accuracy of the models, the paper machine emulation accurately reproduces the, so called, "picketing effect". This effect arises due to the fact that adjacent actuators "fight" each other, see [18, Ch. 15]. It took many years for this phenomenon to be fully appreciated in industry, but students are led to understand the ideas quite quickly by the way in which the associated emulation laboratory is structured.

\section{TyPiCAL USE OF THE MODELS IN A TEACHING ENVIRONMENT}

When using the laboratories, students are presented with an industrial process. The students are then introduced to a particular facet of the process to minimize the scope. The emulations parallel the typical evolution of the associated design process in industry. That is, one typically starts with a simple architecture and then studies its shortcomings and limitations. Thus students face a sequence of issues of increasing complexity. This is matched to the way that the designs are actually arrived at in practice (over many years). Also, at appropriate times, students are challenged with theoretical questions which are intended to prepare them for the next phase of the design (without totally "giving the game away"). Rarely are students given the full process models. Indeed, part of the challenge is to combine phenomenological modeling with on-line data collection to build control relevant models. Again this reflects the approach typically used in industry.

An excerpt from a VLCSD student manual is given below: 


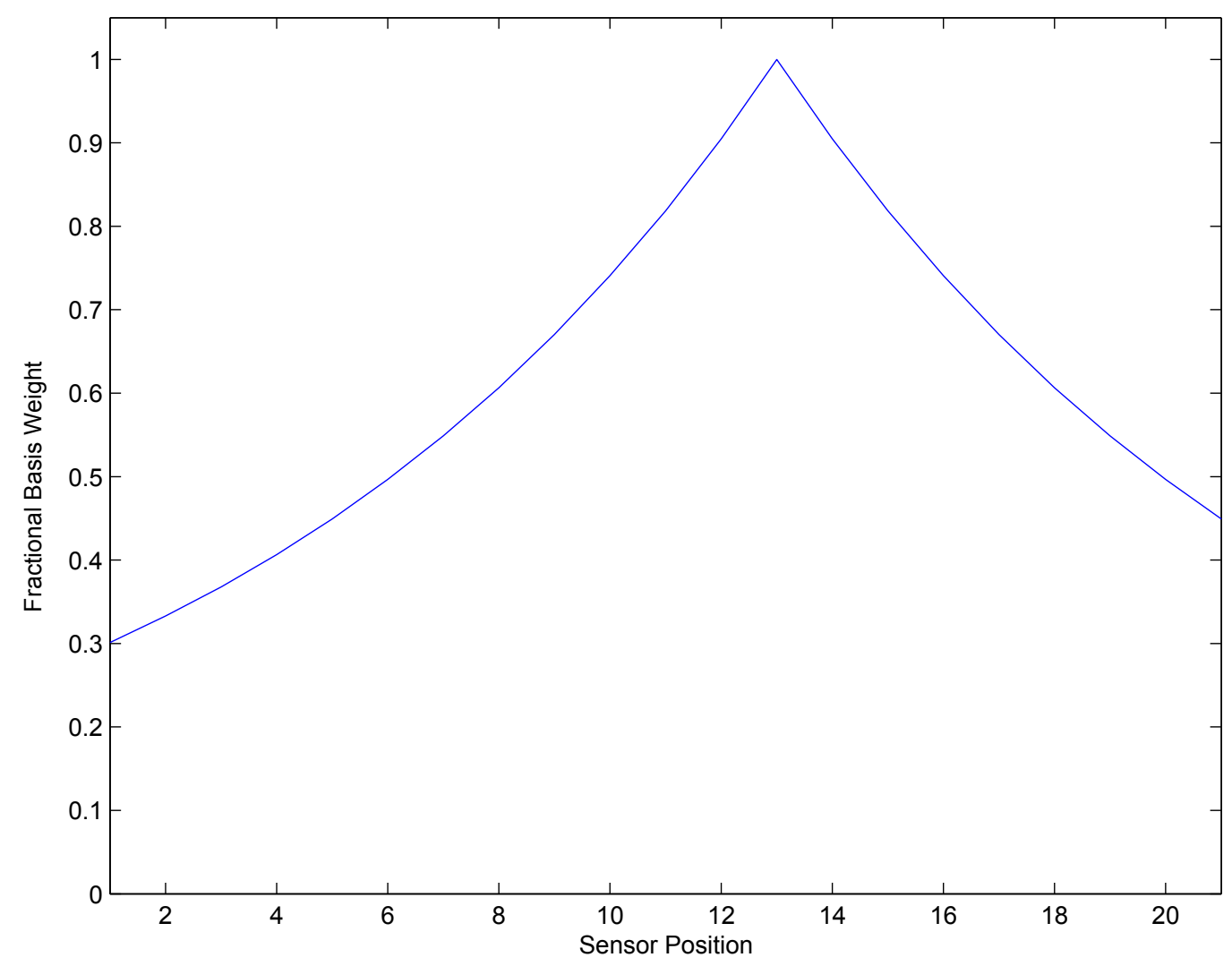

Fig. 6. Basis Weight Profile for a Single Slice Lip Actuator

\section{PMa.5 Simple SISO design with PI controllers}

A first approach to control the web forming process is to use a set of SISO PI controllers. One may correctly suspect that this approach will not achieve very good results since by doing this we are effectively ignoring the multi-variable interactions in the system.

Question PMa.5 (Background Theory)

Assume that the system's model is simply given by

$$
\mathbf{y}(s)=\left[\begin{array}{ccc}
\frac{1}{s+1} & & 0 \\
& \ddots & \\
0 & & \frac{1}{s+1}
\end{array}\right] \mathbf{u}(s)
$$

Design a SISO PI controller that has the structure

$$
C(s)=k_{P}+\frac{k_{I}}{s}
$$

to give a nominal SISO closed loop transfer function

$$
T(s)=\frac{1}{0.1 s+1}
$$

for each actuator-sensor pair. (Note we are ignoring interactions!)

\section{Question PMa.6 (Using the Laboratory)}

Click the Controller block and choose the SISO tab, enter $K_{P}$ and $K_{I}$ then click OK. Click the Disturbance Profile block and choose a disturbance. Observe the closed loop system response.

Pay attention to:

- the achieved closed-loop settling times for each system output. How do they compare to the expected settling times based on the controller design?

- the "shape" of the closed-loop time response. How does it compare to the designed first order response in (5)? 


\section{STUDENT FEEDBACK}

The laboratories are currently in use at eight international universities (four in Australia, two in the United Kingdom, one in Singapore, and one in Malaysia). In general, student feedback has been very positive.

\section{A. Qualitative Feedback}

Feedback is available from students at several of the institutions and is very encouraging.

Typical student feedback comments are:

"The fact of having the laboratory in a virtual form and therefore having access to it whenever I wanted was great."

and

"The best aspect with respect to the handbook was the structure of it, the tasks are very well documented and increase gradually in difficulty.".

But perhaps of greater relevance were the comments from practicing engineers attending control workshops that were conducted using emulation-based laboratories. Some typical comments from these users were:

"As a recent graduate now working as a process control engineer I found it very beneficial to be able to experiment and test different control strategy on process that are very typical in industry. On a working plant it would be very rare to have the freedom to experiment with and test new control strategies."

"Probably the most important aspect of the virtual laboratory is the range of real industrial control problems that can be undertaken. This certainly helps to generate interest and a feeling of purpose in what you are doing not just reading values of an oscilloscope."

"This lab definitely complements the learning I received while at university. It covered aspect and challenges very typical to an industrial process. It introduced me to new thinking for handling nonlinear or "sticky" valves by using a dither to eliminate there unwanted effect.".

Comments from students at other universities include the statement that they can do the experiments at their own choice of place and time (often in a favorite coffee shop). The main negative comment is that students do not get to touch the physical apparatus. However, the reality is that students would never be able to "touch" the corresponding real world system. Moreover, even in industry, control engineers typically interact with the process via a computer interface which is therefore faithfully reproduced in the emulation laboratories.

\section{B. Quantitative Feedback}

A statistical assessment of the impact of the virtual laboratories was carried out by one of the authors. The laboratories were used in 2008 and 2009, and the results presented in Table I are the average score normalized by the corresponding score for 2007 (i.e., prior to the use of emulation-based laboratories).

The percentage improvements listed in Table I are for the following two questions.

Question 1:

"How effective were the supporting resources used in this course in helping you to learn?"

Question 2:

"Overall, how effective was this course in helping you to learn?"

In addition, students were asked to score the following specific question. "Did Virtual Laboratory Experiments and Animated Interactive Web-based Tutorials give you a sense of real relevance of control systems theory in solving industry problems?". The average scores for respondents were as shown in Table II.

The results from Table I show that the use of virtual laboratories produced a significant improvement in students' positive opinion of the learning resources. But more importantly, the results from Table II show that students perceived a very high degree of industrial relevance from the use of virtual laboratories in the learning of control system theory and application. 


\begin{tabular}{l|c|c|c} 
& Percentage Change 2008 & Percentage Change 2009 Group A & Percentage Change 2009 Group B \\
\hline Question 1 & $25 \%$ & $20 \%$ & $16 \%$ \\
Question 2 & $17 \%$ & $9 \%$ & $8 \%$
\end{tabular}

TABLE I

NORMALISED RESPONSES DIRECTLY INFLUENCED BY THE USE OF VIRTUAL LABORATORIES.

\begin{tabular}{l|c} 
Year & Average Score \\
\hline 2008 & 5.89 out of a maximum of 7 \\
2009 Group A & 5.67 out of a maximum of 7 \\
2009 Group B & 5.58 out of a maximum of 7
\end{tabular}

TABLE II

STUDENT RESPONSE TO INDUSTRIAL RELEVANCE OF VIRTUAL LABORATORIES.

\section{The Value Proposition}

Emulation-based experiments are a cost-effective option. They avoid the purchase of hardware and the associated space, demonstrator and occupational health and safety issues. The latter can amount to many thousands of dollars per student place. By way of contrast, emulation laboratories typically cost a few dollars per student place. When one adds the fact that emulation-based laboratories can cover real world systems (rolling mills, paper machines, rockets) that are clearly impossible to provide in a physical form in a university environment, then the value proposition becomes even clearer. Of course, students should, at some point, also experience simple physical apparatus (servo kits, fluid level systems, the inverted pendulum and the like). Thus, emulation type laboratories should be viewed as being complementary to physical laboratories rather than a replacement for them.

\section{CONCLUSions}

This paper has argued the case for a strong link in control engineering education between basic theory (on the one hand) and engineering design reality (on the other). It has been argued that both PBL and RBL are valuable tools but are not the full answer. The paper has identified one solution for bringing students closer to design reality by the use of emulation-based Virtual Laboratories. This type of laboratory gives students exposure to the reality of industrial control system design in a structured and user-friendly environment.

The pedagogical strategies and techniques described in this paper are significant to engineering education as they address many of the pressure points currently facing engineering educators: they provide a pragmatic and effective way of delivering authentic laboratory experiments to students who are geographically widely dispersed. The laboratories are cost effective, respond to students' preferences to engage electronically with their studies and do so with a highly industrially focused approach.

\section{REFERENCES}

[1] K. Lewin, Field theory in social science: selected theoretical papers. London:Tavistock: Harpers, 1952.

[2] W. Sher, A. Williams, and R. Sharkey, "The implementation of a university-wide electronic reflective journal to facilitate the development of core skills.," in Procedings 19th Annual Conference of the Australasian Society for Computers in Learning in Tertiary Education (ASCILITE), (Auckland, New Zealand), 8-11 December 2002. ISBN 0-473-091119-4.

[3] A. Maddocks and W. Sher, "Transferring the rapid progress file a personal development tool between disciplines and continents," in CIB W89 International Conference on Building Education and Research, (The University of Salford, UK), pp. 840-851, 9-11 April 2003. ISBN 1-900491-90-7.

[4] J. V. Nickerson, J. E. Corter, S. K. Esche, and C. Chassapis, "A model for evaluating the effectiveness of remote engineering laboratories and simulations in education," Comput. Educ., vol. 49, no. 3, pp. 708-725, 2007.

[5] E. Lindsay, S. Naidu, and M. Good, "A different kind of difference: Theoretical implications of using technology to overcome separation in remote laboratories," International Journal of Engineering Education, vol. 23, no. 4, pp. 772-779, 2007. 
[6] M. Ogot, G. Elliott, and N. Glumac, "An assessment of in-person and remotely operated laboratories," Journal of Engineering Education, vol. 92, no. 1, pp. 57-63, 2003.

[7] J. Ma and J. V. Nickerson, "Hands-on, simulated, and remote laboratories: A comparative literature review," ACM Comput. Surv., vol. 38 , no. 3 , p. $7,2006$.

[8] B. J. Duch, S. E. Groh, and D. E. Allen, eds., The Power of Problem-Based Learning. Stylus Publishing, 2001.

[9] J. Rhem, "Problem-based learning: An introduction," The National Teaching \& Learning Forum, vol. 8, pp. 1-2, 1998.

[10] M. D. Merrill, "A task centered instructional strategy," Journal of Research on Technology in Education, vol. 40, no. 1, pp. 33-50, 2007.

[11] C. E. Hmelo-Silver, "Problem-based learning: What and how do students learn?," Educational Psychology Review, vol. 16, pp. 235-266, September 2004.

[12] S.-E. Chen, "Quality assurance in the context of problem-based learning." Keynote Address, 9-11 June 2005.

[13] J. Sweller, "Cognitive load during problem solving: Effects on learning," Cognitive Science, vol. 12, no. 2, pp. $257-285$, 1988.

[14] M. Albanese and S. Mitchell, "Problem-based learning: A review of literature on its outcomes and implementation issues.," Academic Medicine, vol. 68, pp. 52-81, 1993.

[15] M. Healy, Reshaping the University: New Relationships between Research, Scholarship and Teaching, ch. Linking research and teaching: Exploring disciplinary spaces and the role of inquiry-based learning. Open University Press/Maidenhead, 01 ed., September 2005.

[16] G. Goodwin, Virtual Laboratories for Control System Design, 2009.

[17] G. Goodwin, S. Graebe, and M. Salgado, eds., Control System Design. Prentice Hall, New Jersey, 2001.

[18] G. Goodwin, M. Seron, and J. D. Dona, eds., Constrained control and estimation: An optimisation approach. Springer, 2005.

Graham Goodwin was born in Broken Hill, Australia and educated at the University of New South Wales from where he obtained a B.Sc (Physics), B.E (Electrical Engineering), and Ph.D (Electrical Engineering).

$\mathrm{He}$ is currently Director of an Australian Government Centre of Excellence for Research in Complex Dynamic Systems and Control at the University of Newcastle. He holds the highest academic position of Laureate Professor. He is also a Distinguished Professor at the Universidad Technica Federico Santa Maria (Chile), Harbin Institute of Technology (China) and Northeastern University (China). He holds Honorary Doctorates from Lund Institute of Technology, Sweden and the Technion Israel. He is the co-author of eight books, four edited books, and over 800 technical papers. Graham is the recipient of the Control Systems Society 1999 Hendrik Bode Lecture Prize, a Best Paper Award by IEEE Transactions on Automatic Control, a Best Paper Award by Asian Journal of Control, and 2 Best Engineering Text Book Awards from the International Federation of Automatic Control (IFAC). In 2008 he received the triennial Quazza Medal, the highest research recognition awarded by IFAC and in 2010 he will recieve the IEEE Control Systems Field Award.

Professor Goodwin is a Fellow of IEEE, USA; an Honorary Fellow of Institute of Engineers, Australia; a Fellow of the Australian Academy of Science; a Fellow of the Australian Academy of Technology, Science and Engineering; a Member of the International Statistical Institute; a Fellow of the Royal Society, London and a Foreign Member of the Royal Swedish Academy of Sciences.

Adrian Medioli was born in Newcastle, Australia and educated at the University of Newcastle from where he obtained a B.E (Computer) in 1992 and $\mathrm{Ph} . \mathrm{D}$ (Electrical Engineering) in 2008.

He spent 10 years as a senior systems engineer working on the automation and control of steel manufacturing processes and 2 years as a director of Omni Automation Pty. Ltd. a control engineering and automation company. He is currently a research academic for the Australian Government Centre of Excellence for Research in Complex Dynamic Systems and Control at the University of Newcastle. His research interests include optimization based control strategies such as Model Predictive Control (MPC), stabilization and modeling with particular emphasis on unstable systems, and virtual laboratory development.

Dr. Medioli is a Member of IEEE and holds a Certificate IV in vocational training and assessment with accreditation under the Australian Quality Training Framework (AQTF).

Willy Sher received his B.Sc. Building (Hons), The University of Witwatersrand, 1973 and M.Sc. (by research), Loughborough University of Technology, 1982

He has held the position of senior lecturer at the University of Newcatle, Australia, in the area of Construction Management for the School of Architecture and Built Environment, since 2001. Over this period Willy has held the additional appointments: Deputy Head of School of Architecture and Built Environment, 2002-2004, Head of Discipline of Building, 2005 - 2007 and Assistant Dean (Teaching and Learning), 2007 - present.

Mr Sher is a Fellow of the Australian Institute of Building and a Fellow of the Chartered Institute of Building. His research interests include virtual teamwork, building information modelling, modular construction and pedagogy in construction education. 
Ljubo B Vlacic (SM'99) received the Dipl.Ing. in Electrical Engineering, the MPhil in Electrical Engineering (Control) and the PhD in Electrical Engineering (Control) from the University of Sarajevo in 1973, 1976 and 1986 respectively.

He spent the first eighteen years of his career in Yugoslavia, with both Energoinvest Inc. - Institute for Automatic Control \& Computer Science (IRCA) and the University of Sarajevo, dealing with the design, development and field testing of industrial control systems. Since 1991 he has been with Griffith University, Australia, where he is the Control Systems discipline Convener and the Mechatronic Systems Engineering Program Convener. His research interests and contributions to research span the areas of: control systems, decision theory, intelligent control and computer \& systems engineering; and, the application of these methodologies to industrial automation, mechatronics, intelligent robotics, knowledge management, intelligent vehicles \& transport systems, and engineering education.

Professor Vlacic is a Fellow of the Institution of Engineers, Australia (FIEAust), a Fellow of the Institution of Engineering and Technology(FIET), a Chartered Professional Engineer of Australia (CPEng), a Registered Professional Engineer of Queensland (RPEQ) and a Chartered Engineer, the Engineering Council UK (CEng). Currently, he serves on several editorial boards. He was appointed to chair (i) the International Federation of Automatic Control (IFAC) Technical Committee on Control Education (2002-2008); (ii) Harold Chestnut Control Engineering Textbook Prize Committee of IFAC (2002-2008); (iii) the National Committee for Automation, Control and Instrumentation of the Institution of Engineers Australia (2003 - 2005); and to co-chair (iv) the Education Committee of the IEEE's Control Systems Society (2003-2008). He was named the 2003 Queensland Professional Engineer of the Year by the Queensland Division of the Institution of Engineers Australia; and awarded the 2004 Sir Lionel Hooke Award, by the Australian Council of the Institution of Engineering and Technology IET; the 2004 IEE Achievement Medal (World-wide), IEE United Kingdom and a number of appreciation awards for notable services and contributions.

James S. Welsh was born in Maitland, Australia, in 1965. He received the B.E. degree (Hons. I) in Electrical Engineering in 1997 and Ph.D. 2004, both from The University of Newcastle, Callaghan, NSW, Australia.

During the last several years, he has been actively involved in research projects at the Centre for Complex Dynamic Systems and Control, The University of Newcastle, including Powertrain Control, Model Predictive Control, and System Identification. His research interests include auto-tuning, system identification, and process control. He is currently a Senior Lecturer in the School of ElectricalEngineering and Computer Science, The University of Newcastle. 